\title{
Observations from The EV Project in Q4 2013
}

\author{
John G. Smart
}

February 2014

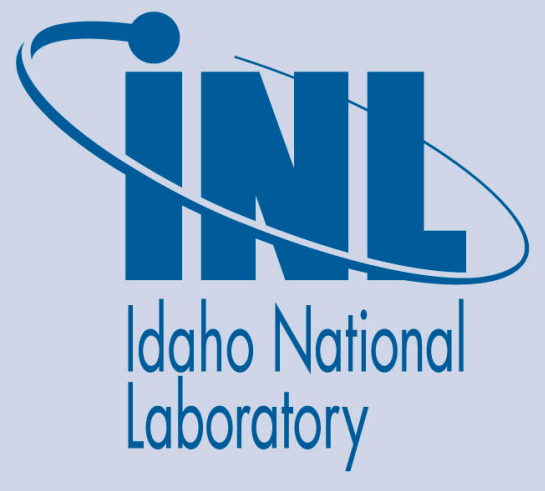

The INL is a U.S. Department of Energy National Laboratory operated by Battelle Energy Alliance 
INL/EXT-14-31462

\section{Observations from The EV Project in Q4 2013}

John G. Smart

February 2014

\section{Idaho National Laboratory \\ Idaho Falls, Idaho 83415}

http://www.inl.gov

Prepared for the

U.S. Department of Energy

Assistant Secretary for Energy Efficiency and Renewable Energy

Under DOE Idaho Operations Office

Contract DE-AC07-05ID14517 


\section{$\stackrel{\exists}{ } \mathbf{V}$ Project}

\section{Observations from The EV Project in Q4 2013}

\section{Fast Facts}

By the end of the $4^{\text {th }}$ quarter (Q4), 2013:

- 124 million miles were recorded on EV Project vehicles

- Over 4.1 million charging events were recorded

- Over 34,000 megawatt-hours of energy were delivered by EV Project charging units

- Over 8,200 Nissan Leafs, Chevrolet Volts and Smart ForTwo Electric Drive vehicles have provided data

- 8,250 residential electric vehicle supply equipment units (EVSE) have reported data

- 3,998 commercial (publicly available, workplace and fleet) EVSE were installed

- 107 DC fast chargers (DCFC) were installed

In Q4 2013:

- DCFC usage frequency dropped $41 \%$ from the previous quarter to 1.3 charging events per DCFC per day. Usage frequency has fallen steadily since the time fees for use of DCFC were initiated during Q3 2013

- DCFCs in the Washington State region had the most frequent usage of any of the regions in Q4, with an average of 2.7 events per DCFC per day

- Public Level 2 charging unit usage frequency increased $19 \%$ from the previous quarter but was still low at 0.31 events per EVSE per day (or 2.2 events per EVSE per week)

- The San Francisco region saw the most frequent public Level 2 EVSE usage, averaging 0.55 events per EVSE per day (or 3.9 events per EVSE week), consistent with the previous quarter

- Charging event duration at public Level 2 EVSE varied widely from region to region, with a low of 2.5 hours per event in Washington, DC and a high of 8.2 hours per charge in Philadelphia

- Residential EVSE across the country saw increased frequency of use for slightly longer durations versus the previous quarter - usage frequency increased $5 \%$ to 0.9 events per EVSE per day and average duration of charging events increased $3 \%$ to 12.3 hours per charging event

- Leaf drivers charged $79 \%$ of the time at home and $21 \%$ away from home (a $1 \%$ increase in home charging from the previous quarter )

- Volt drivers charged $84 \%$ of the time at home and $16 \%$ away from home (a $1 \%$ decrease in home charging from the previous quarter )

- Leafs continued to average 1.1 charging events per day driven

- Volts continued to average 1.5 charging events per day driven 


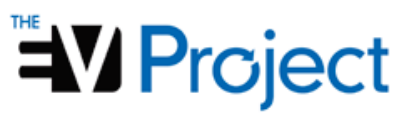

\section{Observations}

\section{Number of participants}

The number of vehicles and residential EVSE in the project reduced slightly in Q4 2013, with no new participants added. Some participants left the project during the quarter.

\section{Public EVSE usage}

DCFC usage nationally decreased $41 \%$ in Q4 from the previous quarter, most likely because the Blink network began charging fees for DCFC use in all project regions during the quarter. The number of DCFC units reporting usage in the quarter was 95 , a $5 \%$ decrease from the previous quarter. This drop may have been due to driver reluctance to pay usage fees, or due to units being out of service. DCFCs in the Washington State region were used most frequently, averaging 2.7 charging events per fast charger per day in the quarter. Washington State, San Francisco, and Los Angeles regional DCFC usage frequency averages were all higher than the national average of 1.3 times per day. In Q4, regional average DCFC event durations ranged from 19 to 28 minutes per charging event and resulted in between 8.8 and $10.5 \mathrm{kWh}$ of energy transferred per event, on average regionally. Average time spent connected per DCFC session increased by $25 \%$ from the previous quarter, perhaps because the usage fee is levied on a persession basis. Public Level 2 EVSE charging events averaged 6 to $11.5 \mathrm{kWh}$ in 2.5 to 8 hours in Q4.

Public Level 2 EVSE usage frequency increased 19\% over the previous quarter, offsetting some of the decrease in DCFC usage. A small number of publicly accessible Level 2 EVSE reported data for the first time during the quarter. However, the total number of publicly accessible Level 2 EVSE reporting usage in the quarter dropped by $5 \%$ from the previous quarter to 2,521 . The national average for the number of charging events per public Level 2 EVSE per day in Q4 was only 0.31 (or 2.2 charging events per EVSE per week). The San Francisco region saw the most frequent public Level 2 EVSE usage of 0.55 events per EVSE per day (or 3.9 events per EVSE week), on average. The San Diego (0.54 events per EVSE day), Los Angeles ( 0.48 events per EVSE day), and Atlanta ( 0.47 events per EVSE day) regions were also above the national average for public Level 2 charging frequency.

EV Project participants averaged 4.4 hours connected to public EVSE per charging event this quarter, up only $2 \%$ from the previous quarter. Duration of plug-in events at public EVSE varied widely from region to region, ranging from 2.5 hours per event in Washington, DC to 8.2 hours per charge in Philadelphia. Time spent drawing power per plug-in event was much more consistent, ranging from 1.9 hours per event in Washington State to 3.0 hours per event in Philadelphia. Overall, utilization of public Level 2 EVSE remained low. The percentage of time EVSE were connected to vehicles in Q4 ranged from less than 1\% in Tucson, Chattanooga, and Houston to $11 \%$ in San Diego. Usage of public Level 2 charging sites is specific to the location and nature of each site, the mix of vehicle makes/models being charged, and other factors. This topic will be explored in a future report. 


\section{$\stackrel{\exists}{ } \mathbf{V}$ Project}

\section{Residential EVSE usage}

Nationwide, residential EVSE saw increased frequency of use and slightly longer charging event durations versus the previous quarter. Usage frequency increased $5 \%$ to 0.9 events per EVSE per day. The national average residential EVSE charging event duration (i.e. the length of time with the EVSE connected to a vehicle per event) was 12.3 hours per event, up $3 \%$ from the previous quarter. Residential EVSE were connected to vehicles from $37 \%$ to $52 \%$ of the day, on average across regions. Vehicles were drawing power from EVSE at home for $7 \%$ to $9 \%$ of the day.

\section{Demand on the Electric Grid}

On any given weekday in Q4, from $50 \%$ to $70 \%$ of residential EVSE were connected to vehicles between midnight and 6:00 AM. Residential EVSE were typically unplugged from their vehicles on weekday mornings between 6:00 AM to 10:00 AM and plugged back in between 3:00 PM and midnight. In regions where electric utilities do not offer widely adopted time-of-use rates for EVs, charging demand on the electric grid from residential EVSE was low during the day and increased gradually in the evening, peaking sometime between 6:00 PM and 10:00 PM. In some of these regions, there was also a small spike in demand at night at a certain point, indicating that some participants were motivated to delay charging until a specific time, even though they may not have realized a financial benefit for doing so. In San Diego and San Francisco, where a large number of project participants have elected EV time-of-use rates, charging demand remained low until spiking sharply at midnight and 1:00 AM.

For publicly available Level 2 EVSE, in most regions, the Q4 median demand begins to rise between 6:00 AM and 8:00 AM, peaks between 9:00 AM and noon, and slowly falls off until midnight. In a few regions where public Level 2 EVSE is not used much, demand falls to near zero between noon and 6:00 PM. In some regions, demand has a second peak in the early afternoon and/or evening.

Charging demand from DCFCs rises after 6:00 AM to a peak around 6:00 PM and falls off to zero by midnight. Aggregate peak demand in Q4 for the 95 DCFCs used was $0.29 \mathrm{MW}$, which was over one third of the peak demand of the 2,521 public Level 2 EVSE used in Q4.

For the full Q4 2013 EV Project charging infrastructure usage report, visit http://avt.inl.gov/pdf/EVProj/EVProjlnfrastructureQ42013.pdf.

\section{Vehicle Charging Location Preference}

Data received from participating Nissan Leafs and Chevrolet Volts was analyzed to determine the percentage of charging events performed at home and away from home. Excluding the 5\% of charging events performed at an unknown location, Leaf drivers performed $79 \%$ of their charging events at home and $21 \%$ away from home in Q4. Leaf charging location preference remained steady in 2013 - the split was 78\% home / 22\% away in Q3, 79\% / 21\% in Q2 2013, and 78\% / 22\% in Q1 2013. Regionally in Q4, Leaf drivers in Memphis and Philadelphia had the strongest preference for home charging of any region, with $93 \%$ home / $7 \%$ away in both 


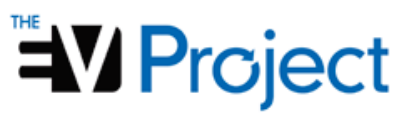

regions. Knoxville saw the highest away-from-home charging preference in Q4, with $72 \%$ home / 28\% away. Leaf drivers in Los Angeles and San Francisco charged nearly as often away from home, with $73 \%$ home / $27 \%$ away and $75 \%$ home / $25 \%$ away, respectively.

The national average for Volt drivers in Q4 was 84\% home / 16\% away. The charging location split for Volts was $85 \%$ / 15\% for the three previous quarters in 2013. Volt drivers in Memphis had the highest regional at-home charging percentage in Q4, with 94\% home / 6\% away. Knoxville and Los Angeles showed the strongest preference for away-from-home charging, with $80 \%$ home / $20 \%$ away and $82 \%$ home / $18 \%$ away, respectively.

\section{Vehicle Charging Frequency}

In each quarter since the beginning of the project, including in Q4, Leafs drivers have averaged 1.1 charging events per vehicle per day when the vehicle was driven. This average has varied regionally between 1.0 and 1.3 charging events per vehicle day.

Volt drivers in Q4 charged 1.5 times per vehicle per day driven, on average nationally. Since the beginning of the project, this average has stayed between 1.4 and 1.5 charging events per vehicle day driven. In Q4, regional charging frequency ranged from 1.3 events per vehicle per day in San Diego, Chattanooga, and Los Angeles to 1.6 events per vehicle per day in Chicago, Washington State, Knoxville, and Oregon.

\section{Driving Distance}

Leaf drivers averaged 26.7 miles per vehicle day nationally in Q4 (considering only days when the vehicle was driven). This was a decrease of 1.7 miles from the previous quarter's average. Regional average daily driving distance ranged from $24.7 \mathrm{mi}$ per vehicle day driven in Philadelphia and Washington, DC to 29.4 mi per vehicle day driven in Oregon.

Volts averaged 39.8 miles per vehicle day driven nationally in Q4, which was a decrease of less than $1 \%$ from the previous quarter. Regionally, Volt average distance per day in Q4 ranged from $35.5 \mathrm{mi}$ per vehicle day driven in Oregon to $50.2 \mathrm{mi}$ per vehicle day driven in Chattanooga. (Note that there is a small number of Volts in Chattanooga so atypical behavior by just one or two drivers could skew the average.)

Volts averaged $49 \%$ more miles per vehicle day driven than the Leaf national average. This trend of Volts driving considerably farther per day than Leafs was consistent across all regions. Although Volt drivers averaged nearly 13 miles more miles each day than Leaf drivers, the average distance driven between charge events per vehicle for Leaf and Volt drivers was much closer, due to higher Volt charging frequency. Leafs averaged 23.9 miles between charges and Volts averaged 27.2 miles between consecutive charging events.

Because the Volt is an extended range electric vehicle, the vehicle may operate in either electric-only (EV) mode or extended range mode after the EV mode range has been exhausted. In Q4, Volts averaged $71 \%$ of their miles in EV mode, down from $73 \%$ in the previous quarter. Regional EV mode driving varied from $55 \%$ in Chattanooga to $76 \%$ in Phoenix. 


\section{$\stackrel{\exists}{ } \mathbf{V}$ Project}

For the full Q4 2013 EV Project Leaf and Volt reports, visit http://avt.inl.gov/pdf/EVProj/EVProjectNissanLeafQ42013.pdf and http://avt.inl.gov/pdf/EVProj/EVProjectChevroletVoltQ42013.pdf

For all Q4 2013 EV Project reports and past reports visit http://avt.inl.gov/evproject.shtml

For an explanation of these reports, visit http://avt.inl.gov/pdf/EVProj/EVProjectTestingReportsDiscussion.pdf

\section{About The EV Project}

The EV Project was the largest electric vehicle infrastructure demonstration project in the world, equally funded by the United States Department of Energy through the American Recovery and Reinvestment Act and private sector partners. The EV Project deployed over 12,000 alternating current Level 2 electric vehicle supply equipment (EVSE) charging stations for residential and commercial use, as well as over 100 dual-port direct current fast chargers (DCFCs). In conjunction with the usage data from approximately 8,300 Nissan LEAF ${ }^{\mathrm{TM}}$, Chevrolet Volts, and Smart ForTwo Electric Drive vehicles, this project collected data from the vehicles and charging infrastructure that totaled almost 125 million miles and 4 million charging events.

The data collection phase of the EV Project ended at the end of 2013. Therefore, the Q4 2013 quarterly reports are the last quarterly reports issued by The EV Project. However, Idaho National Laboratory will continue to analyze data and publish summary reports, technical papers, and lessons learned on vehicle and EVSE use.

This material is based upon work supported by the DOE under Award Number DE-EE-0002194. 